\title{
Rendimento do quiabo adubado com esterco bovino e biofertilizante
}

\section{Okra yield fertilized with bovine manure and biofertilizer}

\author{
Ademar Pereira de Oliveira ${ }^{1 *}$; Arnaldo Nonato Oliveira ${ }^{2}$; \\ Ovídio Paulo Rodrigues da Silva ${ }^{3}$; Suany Maria Pinheiro ${ }^{4}$; Antonio Dantas Gomes Neto ${ }^{4}$
}

\section{Resumo}

O trabalho foi realizado, no período de janeiro a julho de 2011, na Universidade Federal da Paraíba, em Areia-PB, com o objetivo de avaliar o efeito de esterco bovino e biofertilizante sobre o comportamento produtivo do quiabeiro. O delineamento experimental empregado foi de blocos casualizados, com quatro repetições em esquema fatorial $6 \times 2$, com os fatores doses de esterco bovino $\left(0,15,30,45\right.$ e $\left.60 \mathrm{t} \mathrm{ha}^{-1}\right) \mathrm{e}$ com e sem biofertilizante. A massa média de frutos comerciais de quiabo com e sem biofertilizante foi 18 e 16,5 g, respectivamente, nas doses de 27,5 e $60 \mathrm{tha}^{-1}$ de esterco bovino. O número de frutos planta $\mathrm{a}^{-1}$ sem biofertilizante foi 30 frutos planta ${ }^{-1}$ de quiabo na dose de $60 \mathrm{t} \mathrm{ha}^{-1} \mathrm{e}$ com biofertilizante, o número de frutos planta ${ }^{-1}$ foi de 33 frutos na dose $28 \mathrm{t} \mathrm{ha}^{-1}$ de esterco bovino. A produtividade de frutos comerciais de quiabo sem biofertilizante foi de $20,4 \mathrm{tha}^{-1}$ e de $22 \mathrm{t} \mathrm{ha}^{-1}$ com biofertilizante, respectivamente, nas doses de 60 e $31 \mathrm{t} \mathrm{ha}^{-1}$ de esterco bovino.

Palavras-chave: Abelmoschus esculentus, adubação orgânica, produção

\begin{abstract}
The use of bovine manure becomes an useful and economic practice for the small and medium producers of vegetables, and the okra plant normally demands high doses of organic fertilizers. This study was carried out, from January to July 2011, at the Federal University of Paraíba, in Areia city - PB, aiming to evaluate the effect of bovine manure and biofertilizer on the productive behavior of the okra plant. The experimental design used was randomized blocks, with four repetitions in factorial scheme $6 \times 2$, with the doses factors of bovine manure $\left(0,15,30,45\right.$ and $\left.60 \mathrm{t} \mathrm{ha}^{-1}\right)$ with and without biofertilizer. The average mass of commercial fruit of okra, with and without biofertilizer was 18 and $16.5 \mathrm{~g}$, respectively, in the doses of 27.5 and $60 \mathrm{t} \mathrm{ha}^{-1}$ of manure. The number of fruit plant ${ }^{-1}$ without biofertilizer was 30 fruits plant ${ }^{-1}$ of okra in the dose of $60 \mathrm{t} \mathrm{ha}^{-1}$ and with biofertilizer, the number of fruits plant ${ }^{-1}$ was 33 fruits in the dose of $28 \mathrm{tha}^{-1}$ of bovine manure. The productivity of commercial fruits of okra without biofertilizer was $20.4 \mathrm{t} \mathrm{ha}^{-1}$ and $22 \mathrm{t} \mathrm{ha}^{-1}$ with biofertilizer, respectively, in the doses of 60 and $31 \mathrm{tha}^{-1}$ of bovine manure.
\end{abstract}

Key words: Abelmoschus esculentus, organic fertilization, production

\footnotetext{
${ }^{1}$ Prof. Associado III, Dept ${ }^{\circ}$ de Fitotecnia/Pós-Graduação em Agronomia, Centro de Ciências Agrárias, Universidade Federal da Paraíba, UFPB, Areia, PB. E-mail: ademar@cca.ufpb.br

${ }^{2}$ Discente do Programa de Pós-Graduação em Horticultura Tropical, Universidade Federal de Campina Grande, UFCG, Pombal, PB. E-mail: arnaldo.nonato@hotmail.com

${ }^{3}$ Discente do Programa de Pós-Graduação em Agronomia, UFPB, Areia, PB. E-mail: ovidio_paulo@yahoo.com.br

${ }^{4}$ Discentes em Agronomia, UFPB, Areia, PB. E-mail: suanygp@hotmail.com; netocrisanto@gmail.com

* Autor para correspondência
} 


\section{Introdução}

O quiabo é uma hortaliça muito popular em regiões de clima tropical e subtropical, devido à rusticidade das plantas, principalmente, à tolerância ao calor, além de não exigir grande tecnologia para seu cultivo. No Brasil o quiabo encontra condições climáticas excelentes para o seu cultivo, especialmente nas regiões Nordeste e Sudeste, onde é considerada uma cultura popular, principalmente pelos pequenos produtores (MOTA et al., 2008; OLIVEIRA et al., 2003).

$\mathrm{Na}$ produção atual do quiabeiro inclui o uso abusivo de adubos químicos, causando contaminação química e biológica do solo e mananciais hídricos e aumento de custo de produção (OLIVEIRA et al., 2003). Em face desses aspectos se faz necessário o uso de fertilizantes orgânicos sólidos ou líquidos em quantidades adequadas (TANAKA et al., 2003), porque ele possui bom desenvolvimento vegetativo e produtivo no sistema orgânico de produção, alcançando qualidade adequada às exigências do mercado (SOUZA, 1999).

Nos últimos anos, a utilização de adubos orgânicos sólidos ou líquidos na produção agrícola teve um crescimento acelerado no Brasil em função dos seguintes aspectos: altos custos dos fertilizantes químicos, conservação dos recursos do meio ambiente, a prática de uma agricultura ecológica, melhoria da qualidade dos produtos colhidos, redução de contaminações do solo, água, planta, homem e todos os organismos vivos componentes dos agroecossistemas (ARAÚJO et al., 2007; ALVES et al., 2001). Dentre esses fertilizantes o esterco bovino e o biofertilizante bovino, têm se destacado na produção de hortaliças (ARAÚJO et al., 2007).

A utilização de esterco bovino torna-se uma prática útil e econômica para os pequenos e médios produtores de hortaliças (OLIVEIRA et al., 2007), no entanto, maiores ou menores doses a serem utilizadas dependerão do tipo, textura, estrutura e teor de matéria orgânica no solo e, quando utilizada vários anos consecutivos proporciona acúmulo de nitrogênio orgânico no solo, aumentando seu potencial de mineralização e sua disponibilidade para as plantas (OLIVEIRA et al., 2010). Filgueira (2008) afirma que as hortaliças reagem bem a este tipo de adubação, tanto em produtividade como em qualidade dos produtos obtidos, sendo o esterco bovino a fonte orgânica mais utilizada pelos olericultores que usam solos pobres em matéria orgânica.

O quiabeiro normalmente demanda altas doses de adubos orgânicos, o que é de fundamental importância para sua nutrição e melhoria na produtividade com menor ou nenhum uso de fertilizantes minerais (OKWUAGWU; ALLEHM; OSEMWOTA, 2003). A adubação orgânica contribui de forma decisiva para a melhoria das características do solo, podendo inclusive reduzir o custo de produção da cultura, pois o insumo que mais onera o custo de produção do quiabeiro é o adubo mineral usado no plantio e na cobertura. Contudo, deve-se evitar o uso excessivo de adubos orgânicos o que pode acarretar desenvolvimento vegetativo exuberante, dificultando as colheitas e o controle fitossanitário, entre outros aspectos (TRANI et al., 2012).

Com relação aos adubos orgânicos líquido, o biofertilizante bovino é uma fonte orgânica de baixo custo, principalmente pelo fato da crescente procura por novas tecnologias de produção que apresentem redução de custos e auxilie com a qualidade de vida no planeta. Esses fatos, contudo, têm encorajado pesquisadores e produtores rurais a experimentarem biofertilizantes preparados a partir da digestão aeróbica ou anaeróbica de materiais orgânicos, como adubo em substituição aos fertilizantes minerais (FERNANDES et al., 2000).

O biofertilizante é a designação dada ao efluente líquido obtido da fermentação metanogênica da matéria orgânica e água (SANTOS, 2001). Alves et al. (2001), o definem como resíduo final da fermentação de compostos orgânicos que contêm 
células vivas ou latentes de microrganismos (bactérias, leveduras, algas e fungos filamentosos) e por seus metabólicos. Em hortaliças recomendase o seu emprego por meio de pulverizações semanais no solo ou na folha, diluído em água em proporções que variam de $10 \%$ a $30 \%$, para permitir um desenvolvimento perfeito das plantas, uma vez que apresenta ciclo vegetativo e reprodutivo curto, exigindo uma complementação mais rápida e eficiente (SANTOS, 1992).

As informações sobre uso da adubação orgânica no quiabeiro ainda são limitadas, o que justifica a necessidade de se realizar pesquisas para viabilizar seu emprego como fertilização alternativa. Nesse sentido, o trabalho teve como objetivo avaliar o efeito de doses de esterco bovino e biofertilizante, sobre o comportamento produtivo do quiabeiro.

\section{Material e Métodos}

O trabalho foi realizado, no período de janeiro a julho de 2011, na Universidade Federal da Paraíba, em Areia-PB, com o objetivo de avaliar o número de frutos planta ${ }^{-1}$ e a produtividade de frutos comerciais no quiabeiro adubado com doses de esterco bovino e biofertilizante. O solo da área experimental foi classificado como Neossolo Regolítico, Psamítico típico, textura franca-arenosa, Típico (EMBRAPA, 1999), com as seguintes características química e física: $\mathrm{pH}$ em $\mathrm{H}_{2} \mathrm{O}=5,9 ; \mathrm{P}$ disponível, 10,41 mg $\mathrm{dm}^{-3} ; \mathrm{K}=34,12 \mathrm{mg} \mathrm{dm}{ }^{-3} ; \mathrm{Al}$ trocável $=0,65 \mathrm{cmol}_{\mathrm{c}}$ $\mathrm{dm}^{-3} ; \mathrm{Ca}+\mathrm{Mg}=3,35 \mathrm{cmol}_{\mathrm{c}} \mathrm{dm}^{-3}$ e $12,52 \mathrm{~g} \mathrm{~kg}^{-1}$ de matéria orgânica (EMBRAPA, 1997); areia = $841,50 \mathrm{~g} \mathrm{~kg}^{-1}$; silte $=88,00 \mathrm{~g} \mathrm{~kg}^{-1}$; argila $=70,50$ $\mathrm{g} \mathrm{kg}^{-1}$; densidade global $=1,37 \mathrm{~g} \mathrm{~cm}^{-3}$; densidade de partículas $=2,61 \mathrm{~g} \mathrm{dm}^{-3}$; e porosidade total $=$ $0,47 \mathrm{~m}^{3} \mathrm{~m}^{-3}$. O esterco bovino apresentou a seguinte característica: Nitrogênio $=7,20 \mathrm{~g} \mathrm{dm}^{-3} ; \mathrm{P}=5,2$ $\mathrm{g} \mathrm{kg}^{-1} ; \mathrm{K}=4,9 \mathrm{~g} \mathrm{~kg}^{-1}$; Carbono $=105,85 \mathrm{~g} \mathrm{dm}^{-3}$; matéria orgânica $=182,07 \mathrm{~g} \mathrm{dm}-3$ e Relação $\mathrm{C} / \mathrm{N}=$ 14,10, e o biofertilizante a seguinte composição de macronutrientes em $\mathrm{g} \mathrm{L}^{-1}: \mathrm{N}=0,76 ; \mathrm{P}=0,22 ; \mathrm{K}=$ 0,$27 ; \mathrm{Ca}=0,21 ; \mathrm{Mg}=0,13$ e $\mathrm{S}=0,32$. O solo foi preparado para cultivo por meio de capinas, limpeza da área, levantamento de leirões e abertura de covas de plantio.

O delineamento experimental empregado foi de blocos casualizados, com quatro repetições em esquema fatorial $6 \times 2$, com os fatores doses de esterco bovino $\left(0,15,30,45\right.$ e $\left.60 \mathrm{tha}^{-1}\right)$ e presença e ausência de biofertilizante. A parcela foi constituída por 40 plantas, espaçadas de $1,00 \times 0,50 \mathrm{~m}$, sendo as 20 plantas centrais consideradas úteis.

A instalação da cultura foi por meio de semeadura direta distribuindo-se quatro sementes por cova da cultivar Santa Cruz, com desbaste quinze dias após para duas plantas. A adubação constou apenas das doses de esterco bovino incorporadas nas covas, sete dias antes da semeadura, e nos tratamentos que receberam biofertilizante ele foi fornecido no solo seis litros da solução de $20 \%$ do principio ativo (1,0 litro de biofertilizante e 4,0 litros de água), aos 15 , 30, 45, 60, 75 e 100 dias após a semeadura,

O biofertilizante foi preparado seguindo a metodologia de Santos (1992), que consistiu na fermentação por trinta dias, em recipiente plástico, na ausência de ar, de uma mistura contendo esterco bovino fresco e água na proporção de 50\% (volume/ volume $=v / v)$. Para se obter o sistema anaeróbio, a mistura foi colocada em uma bombona plástica de 200 litros deixando-se um espaço vazio de 15 a 20 $\mathrm{cm}$ no seu interior, sendo fechada hermeticamente, e adaptada uma mangueira à tampa, mergulhando a outra extremidade, num recipiente com água com altura de $20 \mathrm{~cm}$, para a saída de gases.

Durante a condução do experimento foram realizados os tratos culturais, capinas e fornecimento de água pelo sistema de aspersão convencional, com turno de rega de dois dias. As colheitas, em número de dez foram efetuadas a cada três dias, no período de 70 a 140 dias após a semeadura, quando os frutos se encontravam imaturos e com coloração verde intensa. Os frutos colhidos foram transportados para o galpão, para avaliação da massa média de frutos comerciais, o do número 
de frutos planta- ${ }^{1}$ e a produtividade comercial de frutos. Foram considerados frutos comerciais aqueles com comprimento entre 10 e $15 \mathrm{~cm}$, retos, sem deformações e com coloração verde intenso (FILGUEIRA, 2008).

Os resultados foram submetidos a análises de variância e de regressão polinomial, utilizando-se o teste F para comparação dos quadrados médios, empregando-se o "software" SAEG (2008). Na análise de regressão utilizaram-se os modelos linear e quadrático, sendo selecionado aquele capaz de melhor expressar cada característica.

\section{Resultados e Discussão}

A massa média de frutos, o número de frutos planta $^{-1}$ e a produtividade de frutos comerciais de quiabo foram influenciadas $(\mathrm{P}<0,05)$, pelas doses de esterco bovino e sua interação com o biofertilizante.

Figura 1. Massa media de frutos no quiabeiro adubado com esterco bovino e fertilizante.

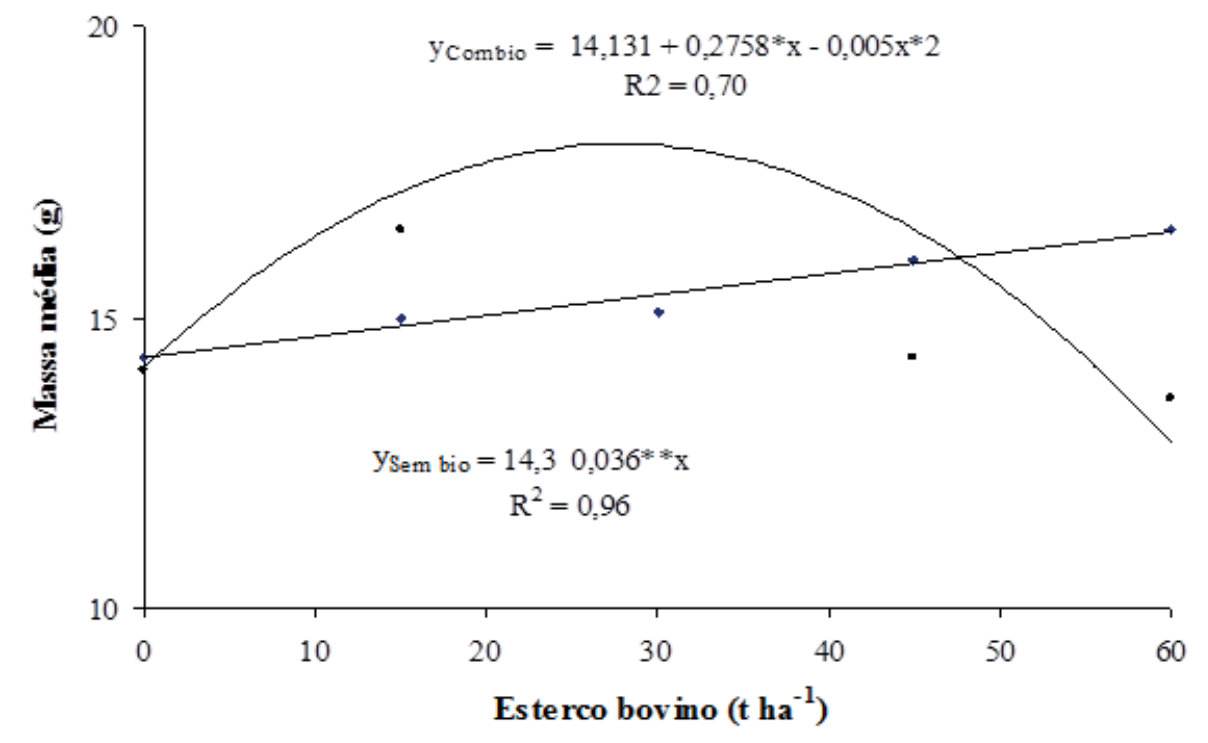

Fonte: Elaboração dos autores.

Utilizando-se o modelo linear em função das doses de esterco bovino, constatou-se que a máxima massa média de frutos comercial de quiabo foi de $16,5 \mathrm{~g}$, obtido na dose máxima de esterco bovino. A massa média máxima de frutos de quiabo em função do fornecimento de biofertilizante foi de $18 \mathrm{~g}$, na dose de 27,5 $\mathrm{t} \mathrm{ha}^{-1}$ de esterco bovino (Figura 1), propiciando ganhos respectivamente, de 78 e $9 \%$, em relação à produção obtida na ausência de esterco bovino e ao peso médio obtido com uso apenas de esterco bovino.

A eficiência verificada do esterco bovino e biofertilizante sobre a massa média de frutos, é atribuída provavelmente, ao fato de que ele se apresenta em uma forma de fácil assimilação, proporcionando aumento na velocidade de infiltração de água, devido à matéria orgânica contribuir para melhoria das condições edáficas, principalmente as propriedades físicas do solo (SILVA et al., 2012), atendendo as exigências nutricionais da cultura, em função do fornecimento equilibrado de macro e micronutrientes, o que permitiu desenvolver o seu potencial genético e resultar em maiores produções (PEREIRA; MELLO, 2002).

O número de frutos planta $^{-1}$ de quiabo sem biofertilizante proporcionou a formação de 30 
frutos na dose de $60 \mathrm{t} \mathrm{ha}^{-1}$ de esterco bovino (Figura de 33 e 34 com uso de $28 \mathrm{t} \mathrm{ha}^{-1}$ de esterco bovino 2). O biofertilizante proporcionou número máximo (Figura 2).

Figura 2. Número de frutos planta ${ }^{-1}$ no quiabeiro com uso de esterco bovino e fertilizante.

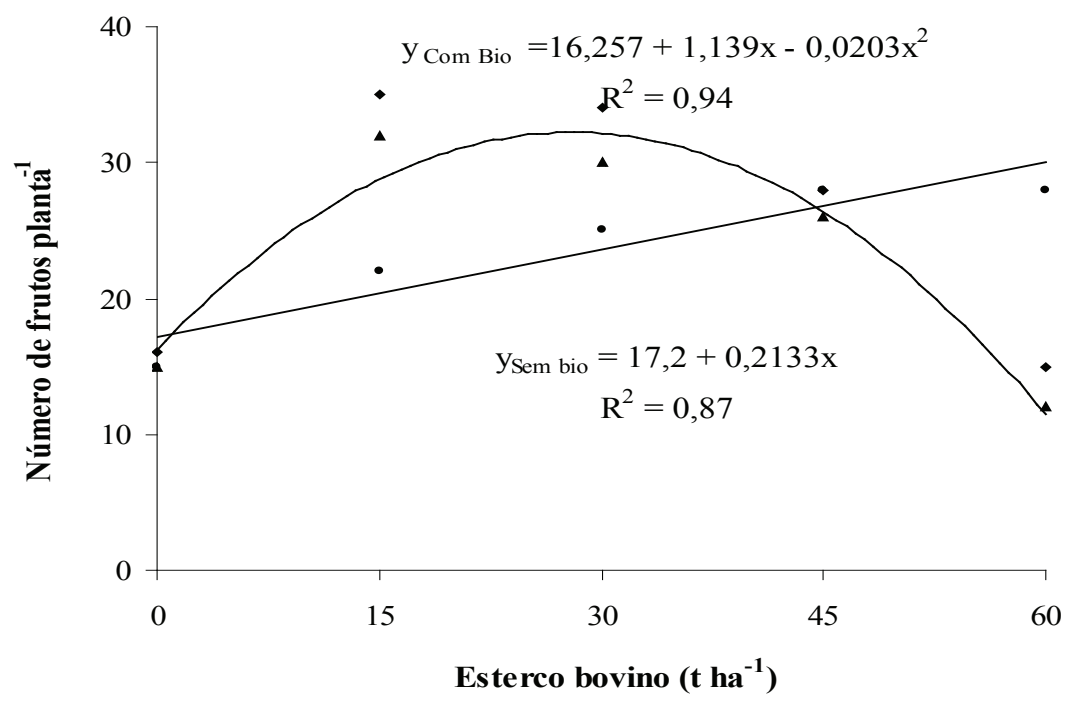

Fonte: Elaboração dos autores.

Adose de 31 tha $\mathrm{a}^{-1}$ de esterco bovino foi responsável pela máxima produtividade de frutos comerciais de 22 $\mathrm{t} \mathrm{ha}^{-1}$, com uso de biofertilizante. Sem biofertilizante a produtividade de frutos comerciais de quiabo foi de 20,4 tha ${ }^{-1}$, na dose de $60 \mathrm{t} \mathrm{ha}^{-1}$ de esterco bovino (Figura 3). Todas as produtividades comerciais de frutos estão dentro da média nacional, entre 20 a 40 $\mathrm{kg} \mathrm{ha}^{-1}$, conforme Filgueira (2008).

Figura 3. Produtividade comercial de quiabo em função de doses de esterco bovino e biofertilizante.

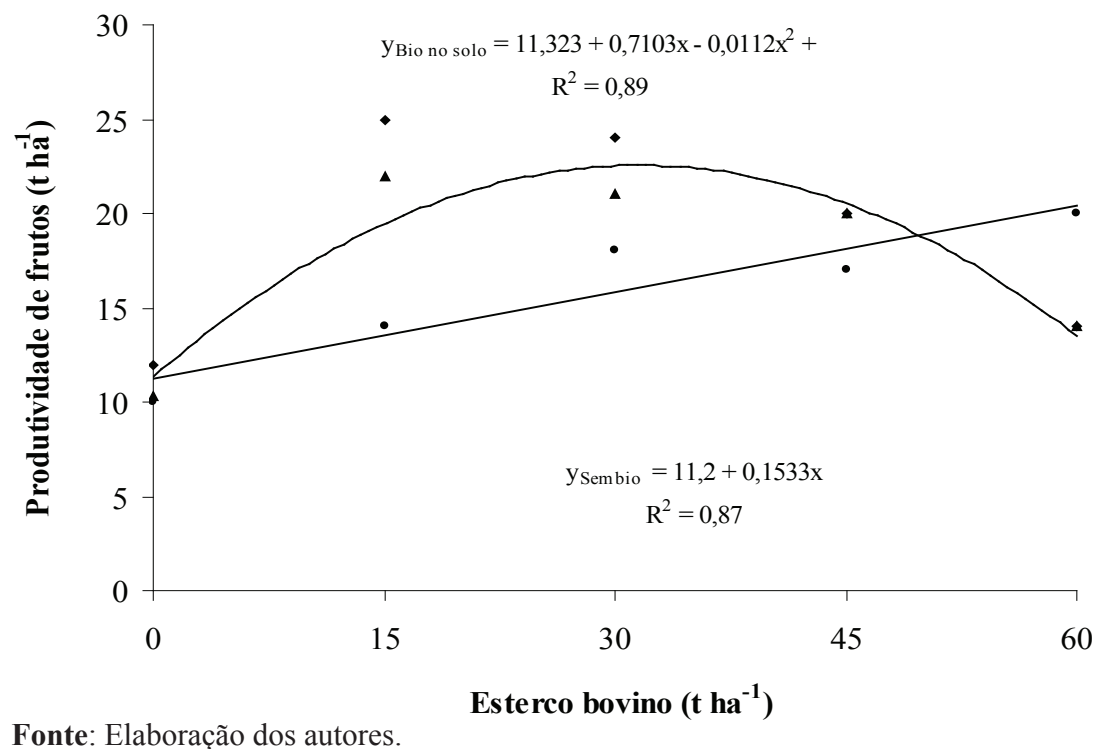


Acombinação de esterco bovino e o biofertilizante resultou em incremento na produtividade de frutos comerciais de $1,6 \mathrm{t} \mathrm{ha}{ }^{-1}$, em relação àquela obtida apena com esterco bovino, o que pode indicar que o uso de biofertilizante contribuiu no atendimento as exigências nutricionais do quiabeiro, possivelmente em função do fornecimento equilibrado de macronutrientes, porque possui sua composição em $g^{-1}: \mathrm{N}=0,76 ; \mathrm{P}=0,22 ; \mathrm{K}=0,27 ; \mathrm{Ca}=0,21$; $\mathrm{Mg}=0,13$ e $\mathrm{S}=0,32$, nutrientes mais facilmente absorvíveis pelas plantas, quando comparados a outros adubos orgânicos (PEREIRA; MELLO, 2002).

De acordo com Souza e Resende (2003), uma das principais alternativas para a suplementação de nutrientes na produção orgânica de hortaliças é a utilização de fertilizantes, isso porque o adubo orgânico é mais eficiente sobre o rendimento das culturas quando associado fertilizantes orgânicos líquidos (NUNES, 2002).

As doses de esterco bovino na presença do biofertilizante fornecido, necessária para proporcionar elevação da massa média de frutos da produção de frutos planta ${ }^{-1}$ e da produtividade de frutos comerciais de quiabo foram praticamente $50 \%$ inferiores àquela necessária na ausência do biofertilizante. Tais resultados estão relacionados não somente com a melhoria geral da fertilidade, mas, também, com melhor absorção de nutrientes. Oliveira et al. (2007, 2010) trabalhando com associação de esterco bovino e biofertilizante em batata-doce, verificaram redução acentuado do uso de esterco bovino quando associado com o biofertilizante. Sediyama et al. (2009), avaliando biofertilizante suíno em quiabeiro verificaram aumento no número e a produção de frutos comerciais planta $^{-1}$ e na produtividade de frutos comerciais.

A resposta do quiabo quanto a massa média de frutos e ao número de frutos por planta e a produtividade de frutos comerciais, em função do emprego de esterco bovino sem biofertilizante, pode estar relacionada ao fato de que quantidades adequadas de esterco bovino de boa qualidade podem ser capazes de suprir as necessidades das plantas em macronutrientes, devido à elevação dos teores de $\mathrm{N}$, $\mathrm{P}$ e K disponíveis, sendo o potássio o elemento cujo teor atinge valores mais elevados no solo, pelo uso contínuo, além de propiciar melhoria das condições físicas do solo, tornando esses elementos altamente disponíveis aos vegetais (RAIJ, 1991; SANTOS et al., 2006), e pela concentração de Nitrogênio $=7,20$ $\mathrm{g} \mathrm{dm}^{-3} ; \quad \mathrm{P}=5,2 \mathrm{~g} \mathrm{~kg}^{-1} ; \mathrm{K}=4,9 \mathrm{~g} \mathrm{~kg}^{-1}$ e matéria orgânica $=182,07 \mathrm{~g} \mathrm{dm}^{-3}$ na sua composição. Palm, Myer e Nandwa (1997) afirmam que os fertilizantes orgânicos podem ser ferramentas essenciais na produção frutos no quiabeiro.

A queda da massa média de frutos, produção de frutos planta $^{-1}$ e da produtividade de frutos comerciais com uso do esterco bovino e biofertilizante, em doses acima daquelas responsáveis pelos máximos valores, pode indicar que possivelmente o aumento das doses de esterco bovino proporcionou desequilíbrio nutricional ao quiabeiro, porque seu uso de forma indiscriminado pode aumentar os teores de nitrogênio no solo e acarretar a sua salinização pela possibilidade de elevação da condutividade elétrica e desequilíbrio nutricional, causando redução da produtividade das culturas (OLIVEIRA et al., 2010).

\section{Conclusões}

O quiabeiro responde bem ao emprego do esterco bovino nas doses de 60 e $31 \mathrm{t} \mathrm{ha}^{-1}$ fornecido de forma isolada ou associada com o biofertilizante, respectivamente;

O esterco bovino ou biofertilizante podem ser utilizados como fertilizantes orgânicos no quiabeiro.

\section{Referências}

ALVES, S. B.; MEDEIROS, M. B.; TAMAI, M. A.; LOPES, R. B. Trofobiose e microrganismos na proteção de plantas: biofertilizantes e entomopatógenos 
na citricultura orgânica. Biotecnologia Ciência \& Desenvolvimento, São Paulo, v. 21, n. 1, p. 16-21, 2001.

ARAÚJO, E. M.; OLIVEIRA, A. P.; CAVALCANTE, L. F.; PEREIRA, W. E.; BRITO, N. M.; NEVES, C. M. L.; SILVA, E. E. Produção do pimentão adubado com esterco bovino e biofertilizante. Revista Brasileira de Engenharia Agrícola e Ambiental, Campina Grande, v. 11, n. 5, p. 466-470, 2007.

EMPRESA BRASILEIRA DE PESQUISA AGROPECUÁRIA - EMBRAPA. Centro Nacional de Pesquisa de Solos. Sistema brasileiro de classificação de solos. Brasília: Produções de Informações, 1999. 412 p.

Centro Nacional de Pesquisa de Solos. Manual de métodos de análise de solo. Rio de Janeiro: Ministério da Agricultura, 1997. $212 \mathrm{p}$.

FERNANDES, M. C. A.; LEAL, M. A. A.; RIBEIRO, R. L. D.; ARAÚJO, M. L.; ALMEIDA, D. L. Cultivo protegido do tomateiro sob manejo orgânico. A Lavoura, Rio de Janeiro, v. 2, n. 1, p. 44-45, 2000.

FILGUEIRA, F. A. R. Novo manual de olericultura: agrotecnologia moderna na produção comercialização de hortaliças. 3. ed. Viçosa: UFV, 2008. 421 p.

MOTA, W. F.; FINGER, F. L.; SILVA, D. J. H.; CORRÊA, P. C.; FIRME, L. P.; RIBEIRO, R. A.Composição mineral de frutos de quatro cultivares de quiabeiro. Ciência $e$ Agrotecnologia, Lavras, v. 32, n. 3, p. 762-767, 2008.

NUNES, M. U. C. Produtividade e principais problemas fitossanitários de cultivares de batata em Sergipe. Horticultura Brasileira, Brasília, v. 20, n. 3, p. 424-427, 2002.

OKWUAGWU, M. I.; ALLEHM, E. I.; OSEMWOTA, $O$. The effects of organic and inorganic manure on soil properties and yield of okra in Nigeria. African Crop Science Conference Proceedings, Egito, v. 6, p. 390-393, 2003.

OLIVEIRA, A. P.; ALVES, A. U.; DORNELAS, C. S. M.; SILVA, J. A.; PÔRTO, M. L.; ALVES, A. U. Rendimento de quiabo em função de doses de nitrogênio. Acta Scientiarum Agronomy, Maringá, v. 25, n. 2, p. 265-268, 2003.

OLIVEIRA,A.P.; BARBOSA,A.H. D.; CAVALCANTE, L. F.; PEREIRA, W. E.; OLIVEIRA, A. N. P. Produção da batata-doce adubada com esterco bovino e biofertilizante. Ciência e Agrotecnologia, Lavras, v. 31, n. 6, p. 17221728, 2007.

OLIVEIRA, A. P.; SANTOS, J. F.; CAVALCANTE, L. F.; PEREIRA, W. E.; SANTOS, M. C. C. A.; OLIVEIRA, A. N. P.; SILVA, N. V. Yield of sweet potato fertilized with cattle manure and biofertilizer. Horticultura Brasileira,
Brasília, v. 28, n. 3, p. 277-281, 2010.

PALM, C. A.; MYER, J. K.; NANDWA, S. M. Combined use of organic and inorganic Nutrient sources forsoil fertility maintenance and replenishment. Soil Science Society of America Special Publication, Wisconsin, v. 6, n. 51, p. 193-217, 1997.

PEREIRA, H. S.; MELLO, S. C. Aplicação de fertilizantes foliares na nutrição e produção do pimentão e do tomateiro. Horticultura Brasileira, Brasília, v. 20, n. 4, p. 597-600, 2002.

RAIJ, B. V. Fertilidade do solo e adubação. Piracicaba: Ceres/POTAFOS, 1991. 343 p.

UNIVERSIDADE FEDERAL DE VIÇOSA - UFV. SAEG: sistema para análise estatística, versão 8.0. Viçosa, MG: Fundação Artur Bernardes, 2008.

SANTOS, A. C. V. dos. A ação múltipla do biofertilizante líquido como fertifitoprotetor em lavouras comerciais. In: ENCONTRO DE PROCESSOS DE PROTEÇÃO DE PLANTAS: CONTROLE ECOLÓGICO DE PRAGAS E DOENÇAS, 2001, Botucatu. Anais... Botucatu: Agroecológica, 2001. p. 91-96.

Biofertilizante líquido, o defensivo da

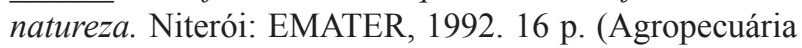
Fluminense, 8).

SANTOS, J. F.; OLIVEIRA, A. P.; ALVES, A. U.; BRITO, C. H.; DORNELAS, C. S. M.; NÓBREGA, J. P. R. Produção de batata-doce adubada com esterco bovino em solo com baixo teor de matéria orgânica. Horticultura Brasileira, Brasília, v. 24, n. 1, p. 103-106, 2006.

SEDIYAMA, M, A. N.; SANTOS, M. R.; VIDIGAL, S. M.; SALGADO, L. T.; PEDROSA, M. W.; JACOB, L. L. Produtividade e estado nutricional do quiabeiro em função da densidade populacional e do biofertilizante suíno. Bragantia, Campinas, v. 68, n. 4, p. 913-920, 2009.

SILVA, J. A.; OLIVEIRA, A. P.; ALVES, G. S.; CAVALCANTE, L. F.; OLIVEIRA, A. N. P.; ARAÚJO, M. A. M. Rendimento do inhame adubado com esterco bovino e biofertilizante no solo e na folha. Revista Brasileira de Engenharia Agrícola e Ambiental, v. 16, n. 3, p. 253-257, 2012.

SOUZA, J. L. Estudos de métodos de nutrição orgânica do quiabeiro (Abelmoschus esculentus). In: CONGRESSO BRASILEIRO DE OLERICULTURA, 39., 1999, Tubarão. Resumos... Tubarão: Associação Brasileira de Horticultura, 1999. Suplemento SOB. (Resumo 375).

SOUZA, J. L.; RESENDE, P. Manual de horticultura orgânica. Viçosa: Aprenda Fácil, 2003. 564 p.

TANAKA, M. T.; SENGIK, E.; SANTOS, H. S.; HABEL JÚNIOR, C.; SCAPIM, C. A.; SILVÉRIO, 
L.; KVITSCHAL, M. V.; ARQUEZ, I. C. Efeito da aplicação foliar de biofertilizantes, bioestimulantes e micronutrientes na cultura do tomateiro (Lycopersicon esculetum Mill.) Acta Scientiarum. Agronomy, v. 25, n. 2, p. 315-321, 2003.
TRANI, P. E.; PASSOS, F. A.; TEODORO, M. C. C. L.; SANTOS, V. J.; FRARE, P. Calagem e adubação para a cultura do quiabo. Disponível em: <www.iac.sp.gov.br/ tecnologias/quiabo/ calagem quiabo.htm>. Acesso em: 9 mar. 2012. 